\title{
CLINICOPATHOLOGICAL STUDY OF SKIN ADNEXAL TUMORS: A SINGLE INSTITUTE EXPERIENCE
}

\author{
BARTOS V.
}

\author{
Martin Biopsy Center, Ltd., Martin, Slovakia
}

\begin{abstract}
A b s t r a c t
Background: Skin adnexal tumors (SATs) encompass a very broad variety of rare dermatopathologic entities.

Objective: The aim of the present study was to analyze an incidence and clinicopathological findings of patients with biopsy-proven ASTs.

Material and Methods: A retrospective review of all consecutive cutaneous tumors that were diagnosed at the Martin Biopsy Center in Martin from July 2019 to March 2021 was carried out. ASTs have been searched for from this file and studied based on their histologic type and line of differentiation, anatomic distribution, age, and gender.

Results: Among over 3,700 skin tumors a total of 38 ASTs in 38 individuals (21 males, 17 females) have been found. The age of the patients ranged from 22-89 years (mean $55.5 \mathrm{y}$.). The head and neck region was found to be the most common site affected $(26 / 38 ; 68.4 \%)$, followed by extremities $(8 / 38 ; 21.1 \%)$ and trunk $(4 / 38 ; 10.5 \%)$. Tumors of hair follicle origin constituted the largest category $(22 / 38 ; 57.9 \%)$, followed by sweat gland tumors $(15 / 38 ; 39.5 \%)$ and tumors derived from sebaceous glands $(1 / 38 ; 2.6 \%)$. Benign lesions accounted for all 38 cases. Trichoepithelioma was the most frequent lesion found in the category of follicular tumors and poroma was the most common among tumours with sweat gland differentiation.

Conclusion: An overall incidence of ASTs is low and in this institutional study they constituted about $1 \%$ of all cutaneous neoplasms. ASTs display a marked phenotypic heterogeneity, that is why many published studies have provided divergent results concerning their clinicopathological features.
\end{abstract}

Key words: skin adnexal tumors, trichoepithelioma, poroma, pilomatrixoma

\section{INTRODUCTION}

Skin adnexal tumors (SATs) encompass a very broad variety of rare dermatopathologic entities (1-3). Based on histogenetic origin they are classified into tumors with differentiation towards hair follicle, eccrine or apocrine sweat glands, and sebaceous glands (1-3). SATs principally arise from undifferentiated pluripotent stem cells present in the epidermis or appendageal structures that finally differentiate to specific tumors (4-6). This neoplastic transformation is a multifactorial process which is related to genetic background, activation of particular molecular pathways, epithelial-mesenchymal interplays, and local tissue microenvironment (5-7). That is why ASTs may sometimes display more than one line of appendageal differentiation, making precise classification of these neoplasms difficult (1-4). ASTs are generally infrequent and the vast majority of them are benign lesions without any prognostic impact (1-4). However, particular types of ASTs have got importance because they may herald complex hereditary syndromes and significant association with certain visceral malignancies (Table 1). Therefore, a correct diagnosis is essential to alert the clinicians to the possibility of these conditions and may have important therapeutic implica-

Corresponding author: MUDr., PhDr. Vladimír Bartoš, PhD., MPH; e-mail: vladim.bartos@gmail.com (C) 2021 Bartos V.

This work is licensed under the Creative Commons Attribution-NonCommercial-NoDerivs 4.0 License (https://creativecommons.org/licenses/by-nc-nd/4.0/) 
tions. ASTs have a peculiar clinical manifestation, they can occur as solitary lesions or with multiple papules, nodules, or plaques $(1,2)$. Syndromic cases of ASTs are usually multiple (1). Dermoscopy does not reveal pathognomonic features and in most cases diagnosis is possible only on the basis of microscopic investigation (1). Although many lesions show remarkable variability in histological appearance, there is a considerable morphological overlap between individual entities (1). ASTs differ greatly not only in histomorphology but also in clinical presentation including age and gender preponderance and body site distribution. In this journal a unique case of a benign follicular tumor - trichoepithelioma with malignant transformation into basal cell carcinoma has been recently published by Bartoš (8). To the best of the author's knowledge, no original research evaluating a large series of AST cases has been published in Slovak medical literature until now. The aim of the present study was to analyze the incidence, spectrum, and clinicopathological findings of patients with biopsy-proven ASTs in a single pathology diagnostic centre. Own observations were then compared with the results of other papers.

\section{MATERIAL AND METHODS}

A retrospective review of all consecutive primary cutaneous tumors that were histologically diagnosed by the author of this article (V.B.) at the Martin Biopsy Center in Martin from July 2019 to March 2021 was carried out. The participants were registered in the Pathology Archive Computer Program, from which the required histopathological data were extracted. The analyzed cases comprised both benign and malignant neoplasms, including common melanocytic nevi and seborrheic keratoses. After completion the ASTs have been searched for from this file. Clinical data of the patients needed for the study were obtained from their medical records. Biopsy samples were processed in the formalin-fixed, paraffin-embedded tissue sections which were stained with hematoxylin and eosin and examined under a light microscope. Most cases of ASTs were also investigated with special staining and immunohistochemical methods as needed in specific situations. Tumors were analyzed based on their histologic type and line of differentiation, anatomic distribution, age, and gender.

\section{RESULTS}

Within the study period the author has investigated over 3,700 various skin tumors. Among them a total of 38 cases (1.02\%) of ASTs in 38 individuals have been found. There were 21 males and 17 females with the male to female $(\mathrm{M} / \mathrm{F})$ ratio of $1.2: 1$. The age of the patients ranged from 22-89 years (mean $55.5 \mathrm{y}$.). Overall most common age groups affected were between 31 and 50 years (29.0\%) and between 51 and 70 years $(29.0 \%)$. The tumors of hair follicle origin constituted the largest group comprising 57.9\% (22/38) of cases. It was followed by sweat gland tumors (15/38; 39.5\%). The tumors derived from sebaceous glands accounted for only a single case $(2.6 \%)$ (Table 2$)$. Sweat gland tumors were more prevalent in males ( $\mathrm{F} / \mathrm{M}$ ratio of $1.5: 1)$, while in follicular tumors the proportion of males and females was equal ( $\mathrm{F} / \mathrm{M}$ ratio of $1: 1)$. The topographical distributions of lesions were diverse. The head and neck region was found to be the most commonly affected site $(26 / 38 ; 68.4 \%)$, followed by extremities $(8 / 38 ; 21.1 \%)$ and trunk $(4 / 38 ; 10.5 \%)$ (Table 3$)$. In the head and neck region, 14 reported cases were from facial and 12 cases from extrafacial parts. In the trunk and limbs, 3 cases were from back, 2 cases from forearm, and 1 each from chest, arm, thigh, shank, foot dorsum, hand dorsum, and finger. Benign tumours accounted for all 38 cases. No malignant neoplasia has been recorded. Trichoepithelioma was the most frequent lesion found in the category of follicular tumors and poroma was the most common among tumours with sweat gland differentiation (Table 4). Histopathology of some types of ASTs is illustrated in Figures 1, 2, and 3. 
Table 1 Most common hereditary syndromes associated with ASTs. (summarized from ref. 1 and 2)

\begin{tabular}{|l|l|l|}
\hline Syndrome & Observed AST & Another important findings \\
\hline Cowden syndrome & trichilemmoma & $\begin{array}{l}\text { breast, renal and endometrial can- } \\
\text { cers, palmoplantar keratosis }\end{array}$ \\
\hline Muir-Torre syndrome & sebaceous tumors & $\begin{array}{l}\text { colorectal, genitourinary, breast, } \\
\text { and hepatobiliary malignancies }\end{array}$ \\
\hline Gardner's syndrome & pilomatrixoma & $\begin{array}{l}\text { gastrointestinal, liver, thyroid, bone, } \\
\text { and brain malignancies }\end{array}$ \\
\hline Rombo syndrome & trichoepithelioma & cutaneous basal cell carcinomas \\
\hline Brooke-Spiegler syndrome & $\begin{array}{l}\text { trichoepithelioma } \\
\text { spiradenoma } \\
\text { cylindroma }\end{array}$ & $\begin{array}{l}\text { specific phenotypic form of disease is } \\
\text { variant }\end{array}$ \\
\hline Birt-Hogg-Dubé syndrome & $\begin{array}{l}\text { fibrofolliculoma } \\
\text { trichodiscoma }\end{array}$ & thyroid and renal cancers \\
\hline Bazex-Dupré-Christol syndrome & trichoepithelioma & cutaneous basal cell carcinomas \\
\hline
\end{tabular}

Table 2 Age incidence distribution of ASTs observed in the present study

\begin{tabular}{|l|c|c|c|c|c|}
\hline Tumor origin & $\mathbf{N}$ & $\mathbf{s} 30 \mathbf{y}$ & $31-50 \mathbf{y}$ & $51-70 \mathbf{y}$. & $\geq 71 \mathbf{y}$. \\
\hline Hair follicle & 22 & $4(18.1 \%)$ & $6(27.3 \%)$ & $6(27.3 \%)$ & $6(27.3 \%)$ \\
\hline Sweat glands & 15 & $2(13.4 \%)$ & $5(33.3 \%)$ & $5(33.3 \%)$ & $3(20.0 \%)$ \\
\hline Sebaceous glands & 1 & 0 & 0 & 0 & $1(100 \%)$ \\
\hline Total & 38 & $6(15.7 \%)$ & $11(29.0 \%)$ & $11(29.0 \%)$ & $10(26.3 \%)$ \\
\hline
\end{tabular}

Table 3 Topographic distribution of ASTs observed in the present study.

\begin{tabular}{|l|l|l|l|l|}
\hline Tumor origin & N & Head \& neck & Trunk & Limbs \\
\hline Hair follicle & 22 & $16(72.7 \%)$ & $1(4.6 \%)$ & $5(22.7 \%)$ \\
\hline Sweat glands & 15 & $9(60.0 \%)$ & $3(20.0 \%)$ & $3(20.0 \%)$ \\
\hline Sebaceous glands & 1 & $1(100 \%)$ & 0 & 0 \\
\hline Total & 38 & $26(68.4 \%)$ & $4(10.5 \%)$ & $8(21.1 \%)$ \\
\hline
\end{tabular}




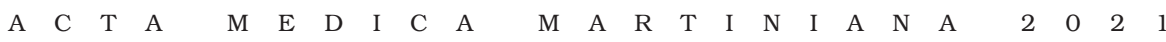

Table 4 Frequency of individual histologic types of ASTs observed in the present study

\begin{tabular}{|l|l|c|c|c|}
\hline Tumor origin & Diagnosis & N & Male & Female \\
\hline Hair follicle & Pilomatrixoma & 7 & 4 & 3 \\
& Classic trichoepithelioma & 9 & 4 & 5 \\
& Desmoplastic trichoepithelioma & 1 & 0 & 1 \\
& Trichoadenoma & 1 & 0 & 1 \\
& Trichofolliculoma & 3 & 2 & 1 \\
& Pilar sheath acanthoma & 1 & 1 & 0 \\
\hline \multirow{3}{*}{ Sweat glands } & Poroma & 7 & 5 & 2 \\
& Hidradenoma & 1 & 1 & 0 \\
& Hidrocystoma & 1 & 0 & 1 \\
& Syringocystadenoma papilliferum & 2 & 2 & 1 \\
& Tubular adenoma & 1 & 1 & 1 \\
\hline \multirow{3}{*}{ Sebaceous glands } & Spiradenoma & 1 & 1 & 0 \\
\hline
\end{tabular}

Table 5 Prevalence of three main histogenetic groups of ASTs based on individual studies (4-7, 9-17). *among a total of 66 ASTs there were two mixed tumors which were not calculated

\begin{tabular}{|l|l|ll|lc|cc|}
\hline & $\begin{array}{l}\text { Total } \\
\text { number }\end{array}$ & \multicolumn{2}{|c|}{$\begin{array}{c}\text { Sweat gland } \\
\text { tumors }\end{array}$} & \multicolumn{2}{c|}{$\begin{array}{c}\text { Hair follicle } \\
\text { tumors }\end{array}$} & \multicolumn{2}{c|}{$\begin{array}{c}\text { Sebaceous gland } \\
\text { tumors }\end{array}$} \\
\hline ref. 4 & 1,016 & 215 & $(21.2 \%)$ & 265 & $(26.1 \%)$ & 536 & $(52.7 \%)$ \\
\hline ref. 7 & 110 & 41 & $(37.3 \%)$ & 43 & $(39.1 \%)$ & 26 & $(23.6 \%)$ \\
\hline ref. 11 & 56 & 24 & $(42.9 \%)$ & 20 & $(35.7 \%)$ & 12 & $(21.4 \%)$ \\
\hline ref. 10 & 96 & 43 & $(44.8 \%)$ & 49 & $(51,0 \%)$ & 4 & $(4.2 \%)$ \\
\hline ref. 5 & 33 & 19 & $(57.6 \%)$ & 12 & $(36.4 \%)$ & 2 & $(6.0 \%)$ \\
\hline ref. 12 & 25 & 14 & $(56.0 \%)$ & 7 & $(28.0 \%)$ & 4 & $(16.0 \%)$ \\
\hline ref. 6 & $66(64) *$ & 20 & $(31.2 \%)$ & 25 & $(39.1 \%)$ & 19 & $(29.7 \%)$ \\
\hline ref. 17 & 60 & 27 & $(45.0 \%)$ & 14 & $(23.3 \%)$ & 19 & $(31.7 \%)$ \\
\hline ref. 13 & 35 & 17 & $(48.6 \%)$ & 11 & $(31.4 \%)$ & 7 & $(20.0 \%)$ \\
\hline ref. 14 & 25 & 13 & $(52.0 \%)$ & 8 & $(32.0 \%)$ & 4 & $(16.0 \%)$ \\
\hline ref. 15 & 30 & 20 & $(66.7 \%)$ & 8 & $(26.7 \%)$ & 2 & $(6.6 \%)$ \\
\hline ref. 16 & 51 & 22 & $(43.1 \%)$ & 19 & $(37.3 \%$ & 10 & $(19.6 \%)$ \\
\hline ref. 9 & 52 & 41 & $(78.8 \%)$ & 4 & $(7.7 \%)$ & 7 & $(13.5 \%)$ \\
\hline this $5 t u d y$ & 38 & 15 & $(39.5 \%)$ & 22 & $(57.9 \%)$ & 1 & $(2.6 \%)$ \\
\hline
\end{tabular}


Fig. 1 Classic trichoepithelioma. The tumor is composed of small irregular basophilic lobules within a dense fibrous stroma. (hematoxylin \& eosin, magnification 20x)

Fig. 2 Pilomatrixoma. The typical biphasic population composed of germinative basaloid cells (black arrow) and eosinophilic ghost cells (white arrow). (hematoxylin \& eosin, magnification 20x)

Fig. 3 Polypoid eccrine poroma. The confluent downward proliferation of the poroma cells with cystic lumina within the tumor. (hematoxylin \& eosin, magnification 10x)
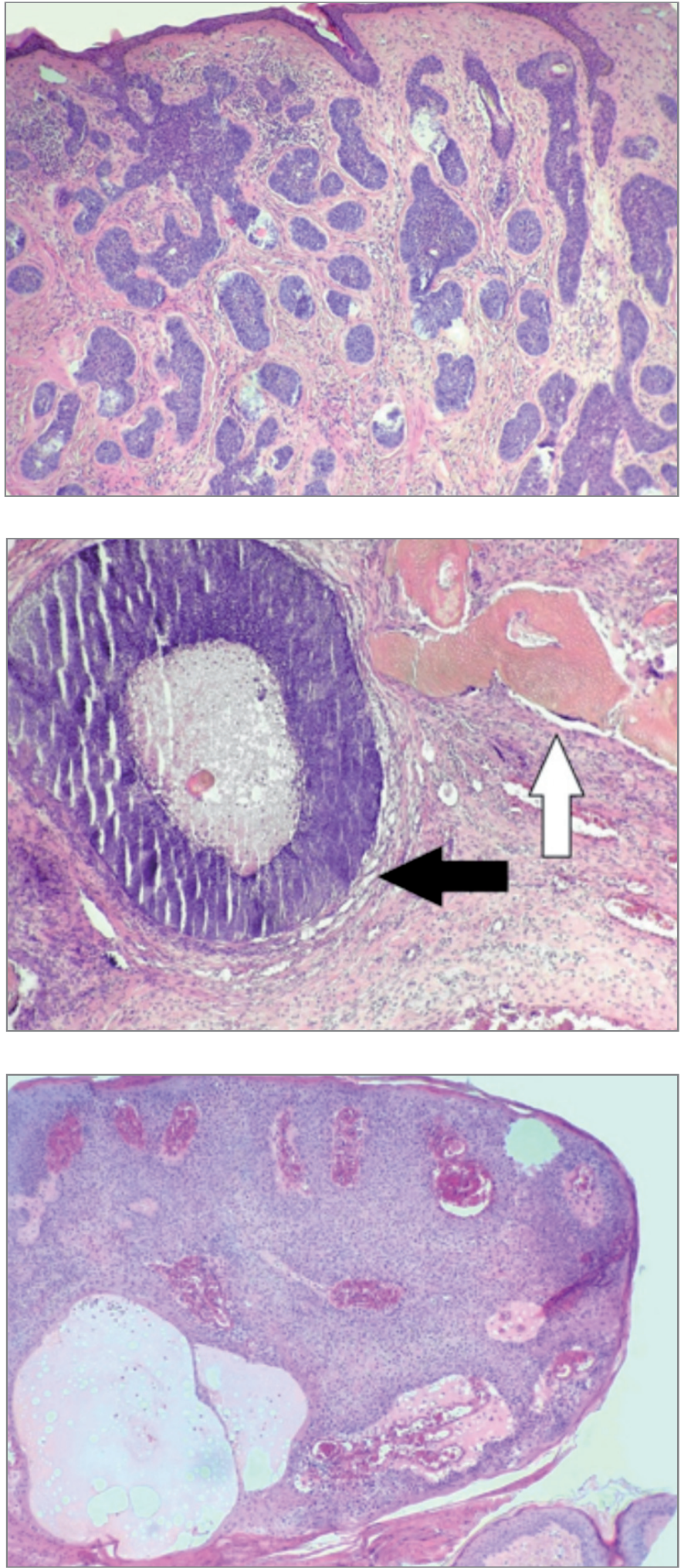


\section{DISCUSSION}

In global literature there is a lack of relevant large-scale epidemiologic studies that are specifically focused on appendageal skin neoplasms. As a consequence no reliable data exist on the geographic and racial incidence of these tumors. In this research the histopathological prevalence of ASTs among over 3,700 consecutive cutaneous tumors was $1.02 \%$. This was similar compared with the study of Samaila (9) who found that ASTs accounted for $0.9 \%$ of all cutaneous neoplasms. Although ASTs constitute a very small proportion of skin tumors in our setting, the true incidence is probably higher than reported because many ASTs are asymptomatic benign lesions that are not troublesome and do not have to be surgically removed.

In the present study the most common line of histogenetic differentiation encountered was follicular differentiation, followed by sweat gland differentiation and by far the least frequent being sebaceous differentiation. These observations are in concordance with that of Suri et al. (6), Kaur et al. (7), and El Ochi et al. (10). Other authors (5,11-16) have reported sweat gland tumors to be the most common, followed by hair follicle tumors. Interestingly, Kamyab Hesari et al. (4) found sebaceous tumors to be the most frequent type, which is unlike of most published studies. This is, however, easily explained because the authors included into this category also sebaceous nevus of Jadasson and sebaceous hyperplasia which are not true neoplasias. In the study of Samaila (9) and Sahu et al. (17) the tumors derived from hair follicle were the least common of all cases. As shown in the Table 5, the percentages of three main varietes of ASTs vary significantly depending on given studies. Even a spectrum of individual histologic types has been very different. As regards hair follicle and sweat gland tumors, the most common types confirmed in our study were trichoepithelioma and poroma, respectively. Other authors have found them as follows: pilomatrixoma \& hidradenoma $(7,10,11,15)$, pilomatrixoma/trichoepithelioma \& hidradenoma (16), trichoepithelioma \& syringoma (5), pilomatrixoma \& hidradenoma papilliferum (12), pilomatrixoma \& spiradenoma (6), pilomatrixoma \& poroma (17), and trichoepithelioma \& acrospiroma (9).

In accord with previous papers we have shown an evident predominance of ASTs in the head and neck region. This is accounted for by the fact that this body site is rich in pilosebaceous units and sweat glands, thereby providing a fertile environment for the development of ASTs. However, the proportional involvements of this area differ markedly (46\% - 88\%) among analyses conducted in various countries (4-7, 9-17).

Concerning age, this study has demonstrated that benign SATs show a very wide range of age distribution. The mean age was 55.5 years while a maximum number of cases were found within the age category of $31-50$ years and $51-70$ years. These values are somewhat higher compared to most published studies. Many authors have confirmed the average age between $32-36$ years $(4,9,10,12,15)$ and the most frequent occurrence in people aged between 20 and 40 years $(6,7,10,12,13,17)$. From the above data one might have concluded that SATs develop most often in younger persons in the third and fourth decades of life. However, several papers have reported data outside of this range. In the study of Nair et al. (5) the tumors were most common in patients under the age of 20, whereas in the research conducted by Sharma et al. (11) they were most frequently found between $51-60$ years. Further, some investigators have noted a bimodal age distribution with two peaks, i.e. between $31-40$ years and $51-60$ years (15), or up to 20 years and then in the fifth decade (9).

As for gender, many published papers have documented $(4,7,9,11,12,15)$ that both sexes are roughly equally affected. Some authors have described a slightly higher preponderance of males $(6,10,17)$, while others have reported a mild predominance of females $(5,13,14,16)$. These discrepancies must have been related to disparate proportions of histologic types of tumors in the study cohorts. It has been well-known that many ASTs develop more commonly at a certain age and affect more frequently a certain gender. For example, trichofolliculoma and chondroid syringoma have a predilection for middle-aged 
men (1). Tubular adenoma most frequently occurs in middle-aged women and sebaceoma in elderly women (1). Melanocytic matricoma has a predilection for elderly men (1). Classic syringoma often occurs in elderly women but its eruptive vatiant is more frequent in young women (1). Syringocystadenoma papilliferum is more common in females and myoepithelioma more frequent in males (1). Hidradenoma papilliferum almost exclusive affects women (1). Hence it is obvious that precise analyzes of demographic data and clinicopathologic findings of ASTs must to take into account their individual histological subtypes and varieties, some of which should be better evaluated separately.

It is also important to note that ASTs, especially their malignant forms, often histologically mimic cutaneous metastases and vice versa (18). Morphologic distinction between primary AST and metastatic malignancy can be very difficult but it has a key impact on further diagnostic and therapeutic management of the patient. The lesions that are sometimes problematic to differentiate are e.g. clear cell nodular hidradenoma vs metastatic clear cell renal cell carcinoma, high-grade porocarcinoma vs metastatic poorly differentiated non-small cell carcinoma or high-grade transitional cell carcinoma, low-grade ductal carcinoma of the skin adnexa vs metastatic low-grade ductal carcinoma of the breast or salivary gland, and basaloid adnexal carcinoma vs metastatic breast carcinoma (18). The subject matter of their differential diagnosis is very complex and this topic would go far beyond the scope of this article. In general, the combination of epidermal involvement, absence of multifocality, lack of Grenz zone, and absence of lymphovascular invasion favours primary malignant AST rather then metastasis (18). Although immunohistochemistry has a limited value in the exact categorization of ASTs, it may help to distinguish primary ASTs from metastatic cancers. Sariya et al. (18) have found that a simultaneous using of four immunohistochemical markers (p63, B72.3, calretinin, CK5/6) may be of help in this regard. Whereas p63 and CK5/6 are positive in virtually all SATs, they are negative in the vast majority of metastatic adenocarcinomas. SATs are usually reactive for calretinin and negative for B72.3, while metastatic cancers are generally positive for B72.3 and negative for calretinin. Anyway, many problematic cases require a thorough clinicopathological correlation and an extensive clinical evaluation is usually necessary to exlude metastasis from elsewhere.

\section{CONCLUSION}

An overall incidence of ASTs is low and in this institutional study they constituted about $1 \%$ of all skin neoplasms. They were prevalent in middle-aged group with a slight predilection for men, the head and neck region was the most frequently affected and the hair follicle tumors represented the most common histogenetic group. ASTs manifest a striking phenotypic heterogeneity, that is why many published studies have shown diverse results regarding their clinicopathological features.

\section{REFERENCES}

1. Elder DE, Massi D, Scolyer RA, Willemze R. WHO Classification of Skin Tumours. 4th Edition, IARC Lyon, 2018. p. 154-222. ISBN 978-92-832-2440-2

2. Kazakov DV, Michal M, Kacerovska D, Mc Kee PH. Cutaneous adnexal tumors. Philadelphia, Wolters Kluwer/Lippincot, Williams \& Wilkins; 2012. ISBN 978-1-60547-854-8

3. Adamicová K, Fetisovová Ž, Mellová Y, Výbohová D. Diagnostika adnexálnych tumorov kože. Čes.-slov. Patol 2006;42(2):59-65

4. Kamyab-Hesari K, Balighi K, Afshar N, et al. Clinicopathological study of 1016 consecutive adnexal skin tumors. Acta Med Iran 2013;51(12):879-885. 
5. Nair PS. A clinicopathologic study of skin appendageal tumors. Indian J Dermatol Venereol Leprol 2008;74(5):550.

6. Suri J, Gupta D, Koul KK, Kumari R. A clinicopathological analysis of skin adnexal tumours: four year retrospective study. JK Science 2016;18(4):248-251.

7. Kaur K, Gupta K, Hemrajani D, Yadav A, Mangal K. Histopathological analysis of skin adnexal tumors: A three year study of 110 cases at a tertiary care center. Indian J Dermatol 2017;62(4):400-406.

8. Bartoš V. Basal cell carcinoma arising within a trichoepithelioma: an immunohistochemical study. Acta Medica Martiniana 2020;20(2):64-71.

9. Samaila MOA. Adnexal skin tumors in Zaira, Nigeria. Ann Afr Med 2008, 7(1):6-10.

10. El Ochi MR, Boudhas A, Allaouni M, et al. Skin adnexal tumors: Histological study about 96 cases. Pan Afr Med J 2015;20:389.

11. Sharma A, Paricharak DG, Nigam JS, et al. Histopathological study of skin adnexal tumours-institutional study in South India. J Skin Cancer 2014:543756, 2014.

12. Pujani M, Madaan GB, Jairajpuri ZS, et al. Adnexal tumors of skin: An experience at a tertiary care center at Delhi. Ann Med Health Sci Res 2016;6(5):280-285.

13. Radhika K, Phaneendra BV, Rukmangadha N, Reddy MK. A study of biopsy confirmed skin adnexal tumours: experience at a tertiary care teaching hospital. J Clin Sci Res 2013;2(1):132-138.

14. Thakuria SK, Deka MK, Das A, Phukan A, Khakhlari NM. A two years study of histopathological spectrum of skin adnexal tumors in a tertiary care centre of Southern Assam, India. Int J Res Med Sci 2020;8(5):1802-1807.

15. Gopidesi DT, Sai PV, Vissa S, et al. Skin adnexal tumors: a histopathological analysis of 30 cases at a tertiary care center. Saudi J Pathol Microbiol 2020;5(2): 67-71.

16. Vani D, Ashwini NS, Sandhya M, Dayananda TR, Bharathi M. A 5 year histopathological study of skin adnexal tumors at a tertiary care hospital. IOSR J Dent Med Sci. 2015;14(4):1-5

17. Sahu A, Sa DK, Nayak SK, Agrawal KC. Skin adnexal tumors: A histopathological study of 60 cases at a tertiary care centre. Annals Pathol Lab Med 2018;5(3):A215-A220.

18. Sariya D, Ruth K, Adams-McDonnell R, et al. Clinicopathologic correlation of cutaneous metastases: experience from a cancer center. Arch Dermatol 2007;143(5):613-620.

Received: April, 14, 2021

Accepted: May, 7, 2021 